\title{
Inflammasome Regulation at the Level of Cellular and Molecular Function affect by Recombinant Tissue Plasminogen Activator and Exosomes Treatment in Ischemic Stroke Animal Model
}

\section{Mohsen Safakhil}

Islamic Azad University

Mina Ramezani ( $\nabla$ mina.ramezani@gmail.com )

Islamic Azad University Central Tehran Branch https://orcid.org/0000-0003-4144-9632

Azadeh Mohamadgholi

Azad University: Islamic Azad University

\section{Research Article}

Keywords: Neuron regeneration, Cell secretion, MCAO

Posted Date: April 30th, 2021

DOl: https://doi.org/10.21203/rs.3.rs-375724/v1

License: (c) (1) This work is licensed under a Creative Commons Attribution 4.0 International License.

Read Full License 


\section{Abstract}

In the current research, neuroprotection and performance improvement have been investigated in MCAO animal model treated with exosomes combined with rt-PA. Middle cerebral artery occlusion (MCAO) was induced in 25 adult male Wistar rats. Rats received rt-PA with a dose of $100 \mu \mathrm{g} / \mathrm{kg}$ in a single dose or drived-exosome from bone marrow MSCs. The Garcia scoring system and elevated body test were employed as behavioral tests for the functional recovery assessment. Cresyl violet staining was applied to evaluate the cell death degree in brain tissues. Immunohistochemical analysis was performed for the detection of GFAP and IBA1-positive cells. Results Cresyl violet staining revealed that the population of dark cells was significantly reduced in all treatment groups. A considerable increase $(P \leq 0.05)$ in catalase enzyme was observed in the combination therapy group compared whit the MCAO group ( $\mathrm{P} \leq$ 0.05). The amount of GPX despite the increase in all treatment groups compared to MCAO group was not statistically significant $(P \geq 0.05)$. Our conclusion was approved by the NIrp1 and NIrp3 downregulation during combination therapy in MCAO model by reduction in cell death rate. The Density of GFAP-positive cells Showed a decrease in the exosome with or without rt-PA experimental groups in comparison with the MCAO group $(P<0.05)$. Our observation indicated that exosomes, in combination with rt-PA, resulted in the noticeable functional recovery, neuronal regeneration, and reduction of neuronal cell death after a 7-day period of the MCAO induction. This novel therapeutic strategy could provide a better treatment option for those patients suffered from stroke.

\section{Introduction}

Brain stroke as the second reason of death is responsible for 1 of 9 deaths and many disabilities through the world and causes major adverse impact in survivors $(1,2)$. Approximately, $90 \%$ of all kinds of brain ischemia that are annually diagnosed in clinic are related to arterial blockade. This type of disturbance resulted by narrowing or clotting of the blood vessels and cause the blood flow reduction and oxygen level, which Leads to the death of neural cells (3). Despite this proportion of stroke deaths, treatment strategies still need to be improved. The reperfusion methods such as prescribing thrombolytic medications or mechanical interventions are able to reanalyze the occluded vessels, facilitating the process of thrombolysis, which improves the treatment outcome after acute ischemic stroke (4). One of the available therapeutic tactics, which is useful only for the first 4.5 hours of the post-stroke period and known as a thrombolytic agent, is recombinant tissue plasminogen activator (rt-PA) (3). The administration of rt-PA is considered the gold standard treatment for acute ischemic stroke. This factor acts a protease by which cleaves plasminogen and converts it into plasmin which, in turn, digests the fibrin clots, leading to the recanalization of the occluded vessels and maintenance of tissue homeostasis (5). One of the newest approach in treatment of stroke based on regenerative medicine is cell-based therapies and applying of cell secretions. Stem cells and their secretions are one of the new strategy that have been revealed an effective outcome during an in vitro assessment. According to previous study, the best time to use cell therapy therapeutic approach is shortly after a stroke (6). Systemic management of MSCs, as a therapy for stroke, has demonstrated that MSCs are capable of enhancing the plasticity and 
neurovascular remodeling of the central nervous system (CNS), leading the improved neural functionality (7). These cells are able to change inflammatory reactions, oxidation components and soluble cytokines secretion and immune-modulatory receptors (8-10). Exosomes are small-membraned vesicles with a diameter of 30 to $120 \mathrm{~nm}$ containing proteins, lipids, coding and non-coding RNAs $(11,12)$. Cell secretions and molecular pathways inside and outside the cell are normally disrupted during a stroke. Therefore, following these changes, it induces an active immune system and destructive reactions in the body, especially in the brain tissue $(7,13)$. Two types of inflammatory responses in reaction to ischemic stroke are NOD-like receptor protein $1 \& 3$ (NLRP1 \& 3)-infammasomes. It has been proposed that these sorts of mediate inflammatory responses increase IL-1 and IL-18 (14). So, the aim of this study was to investigate the synergistic effect of exosomes combination with rt-PA on inflammasome complex in the brain of MCAO animal model.

\section{Materials And Methods}

\section{Ethical issue}

In this study, 25 male Wistar rats (250-300 g) that were kept under standard conditions with free access to food and water ( $45-50 \%$ humidity, $22-24^{\circ} \mathrm{C}, 12 \mathrm{~h}$ : $12 \mathrm{~h}$ light: dark cycle), were used. The methods used in the current research were approved by the ethics committee of Islamic Azad University, Tehran, Iran.

\section{Stem cell isolation and purification}

Five animal were used for Bone marrow mesenchymal stem cells (BMSCs) isolation. BMSCs were isolated from femur and tibia of the male wistar rats $(250-300 \mathrm{~g} / 6-8$ months/ male) and cultured in DMEM (DMEM-F12) containing 10\% fetal bovine serum (Gibco; Germany). The cells were characterized and passaged up to $4^{\text {th }}$ passage of cultivation at $37^{\circ} \mathrm{C}, 5 \% \mathrm{CO} 2$ and $95 \%$ humidity.

\section{Exosome collection from BMSCs}

Cell secretions were collected after each culture media replacement for 14 days, according to our late study (15). Briefly, the supernatant of the culture medium of cells $\nabla$ were centrifuged by ultra-high-speed centrifugation (2000×g for $10 \mathrm{~min}, 10,000 \times \mathrm{g}$ for $30 \mathrm{~min}, 100000 \times \mathrm{g}$ for $60 \mathrm{~min}$, and $100000 \times \mathrm{g}$ for $60 \mathrm{~min}$ ) (16). Exosomes were investigated by western blot assessment for CD9 and CD81 membrane proteins. The exosomes were first isolated by electrophoresis of $6-12 \%$ polyacrylamide gel sulfate sodium dodecyl sulfate (SDS-PAGE). The PVDF membrane was used for transferring of the protein and incubated for 12 hours at $4{ }^{\circ} \mathrm{C}$ along with CD9 and CD81 (Biorbyt Co., UK) and then HRP-conjugated secondary antibody were applied to identify the protein markers. Protein blots were analyzed by luminol (Santa Cruz).

\section{Brain ischemic animal model induction}

Twenty animals were anesthetized using the intraperitoneal injection of $10 \%$ chloral hydrate )Merck, Germany) at a dose of $400 \mathrm{mg} / \mathrm{kg}$ (17). By making an incision in the midline of the neck under a surgical 
microscope, the right common carotid artery and the external and internal carotid arteries, was exposed (Olympus Szx12, Germany). MCAO Was induced in rats by inserting a silicone coat filament through the external carotid artery into the right internal carotid artery (Doccol Corp., Sharon, MA, USA). When it reached the anterior cerebral artery, the process was stopped $(18,19)$. After $60 \mathrm{~min}$, the filament was removed from the internal carotid after $60 \mathrm{~min}$.

\section{Design of study}

The animals were randomly divided into five groups ( $n=5$ per group) as 1$)$ The normal group (Control), 2) The Ischemic group (Ischemic), 3) The Ischemic treated with Exosome (Ischemic + EXO: $100 \mu \mathrm{g})$, 4) The Ischemic + rt-PA group (Ischemic + rt-PA: $100 \mu \mathrm{g} / \mathrm{kg} ; 4 \mathrm{~h}$ after MCAO induction) 5) The Ischemic + Exosome + rt-PA group (MCAO + EXO + rt-PA) for seven days.

\section{Behavioral Assessments}

To perform the analysis of the experimental stroke in rodents, elevated body swing test was conducted by the method of Borlongan and Sanberg. The rats were placed in a clear cage and given 2 minutes to adjust to the environment and be in a neutral position (Set as having all four paws on the floor). Then, the animals were kept on a vertical axis so that they could not deviate more than 10 degrees on either side. The oscillation was marked each time the animal moves its head off the vertical axis to the right or left. Animals that do not have any brain lesions turn their heads evenly in both directions, but animals that have brain lesions on one side of their brain, such as ischemic stroke, are expected to present a dominant/biased swing direction (Ingberg et al., 2015).

\section{Cresyl violet staining}

After separating the rats' brains from the skull, they were fixed overnight. The brain samples were dehydrated by alcohols series with increasing concentration, then they were washed using xylene, and infiltrated with paraffin. The paraffin-embedded specimens were coronally sectioned with a thickness of 5 $\mu \mathrm{m}$ (Licka, USA). The slices were then placed on slides and stained with purple $2 \%$ Cresyl after clearing and rehydration. The samples were then covered with enthlan adhesive and the stained slides were viewed under a light microscope with a magnification of 400 (Labomed, USA). After imaging the slides, the cells around the peri-infarct were counted by the ImageJ software (version 1.8, NIH, Wayne Rasband, and USA). Cell shrinkage, cytoplasm, loss of Nissl body uniformity, pycnotic nucleus and nucleus density were assessed by light microscopy (Labomed, USA).

\section{Real-time PCR}

Total RNA was extracted from $100 \mathrm{mg}$ of brain tissue by use of Qiazol (Qiazol lysis reagent, USA) in sterilized RNase-free tubes. The Revert aid cDNA synthesis kit (Fermentas, Germany) in a volume of $25 \mu \mathrm{L}$ was used, according to the manufacturer's recommendations. The Primer3 software software was used to design the primers and then the primers (Table 1) were approved by the NCBI BLAST Tool. $500 \mathrm{ng}$ of synthesized cDNA was used for the analysis of the relative gene expression by real-time PCR. PCR 
reactions were carried out in a total volume of $25 \mu \mathrm{L}$ containing $12.5 \mu \mathrm{L}$ of SYBR Green Premix $2 \mathrm{X}$ (Takara, Shiga, Japan) and 10 pico-molar of mixed primers. Thermocycling conditions were as the following setting: $95^{\circ} \mathrm{C}$ for $10 \mathrm{sec}$, followed by 40 cycles of denaturation at $94{ }^{\circ} \mathrm{C}$ for $5 \mathrm{sec}$, annealing and extension at $60^{\circ} \mathrm{C}$ for $34 \mathrm{sec}$. to determine the expression of the relative expressions for the N/rp 1 and NIrp-3 genes the $\Delta \Delta \mathrm{CT}$ method was used. The obtained Ct was compared for both the internal control (Gapdh) and the samples.

Table 1. Primer sequence of N/rp1 and N/rp3 genes

\begin{tabular}{|c|c|c|c|c|}
\hline gene & Forward & Reverse & Accession number & Product length \\
\hline Nirp3 & 5' GGAGTGGATAGGTTTGCTGG 3' & 5' GGTGTAGGGTCTGTTGAGGT $3^{\prime}$ & XM_006246458.3 & $163 \mathrm{bp}$ \\
\hline Gapdh & 5' AAG TTC AAC GGC ACA GTC AAG G $3^{\prime}$ & $5^{\prime}$ CAT ACT CAG CAC CAG CAT CAC C $3^{\prime}$ & XM 017593963.1 & $121 \mathrm{bp}$ \\
\hline Nlrp1 & $5^{\prime}$ CAAGAGGGAAAGGTGGACAG $3^{\prime}$ & $5^{\prime}$ GGAAGTGATGGGGATGAAGTGT $3^{\prime}$ & XM 006246755.3 & $183 \mathrm{bp}$ \\
\hline
\end{tabular}

\section{Immunohistochemistry}

The $5 \mu \mathrm{m}$ sectioned brain samples were rehydrated and then incubated in phosphate buffer for $100 \mathrm{~min}$ at $100^{\circ} \mathrm{C}$, then the samples were washed with phosphate buffer (PBS), The blocking process was performed for 30 minutes with $0.4 \%$ Triton X-100 in PBS and goat serum (10\%). In the next step, the sections were incubated with the primary antibody against GFAP (Abcam, Cambridge, United Kingdom) and IBA1 (Abcam, Cambridge, United Kingdom) at the dilution ratio of 1:100 at $4{ }^{\circ} \mathrm{C}$ for overnight, Then, the slides were incubated at $37^{\circ} \mathrm{C}$ for 90 minutes with Peroxidase-conjugated secondary antibodies. Finally by performing 3,3'-diaminobenzidine tetrahydrochloride (DAB) reaction the GFAP or IBA1-positive cells were visualized. The nuclei were stained with hematoxylin. The samples were then viewed under a light microscope (Labomed, USA) at 400X magnification. Then the expression of GFAP and IBA1 in neuronal cells was assessed using the Image $\mathrm{J}$ software.

\section{Terminal dexynucleotidyl transferase-mediated dUTP nick end labeling (TUNEL) assay}

To measure the DNA fragmentation In situ cell death detection method was performed with POD Kit (Roche, Germany). First, the histological sections were incubated whit proteinase $\mathrm{K}(15 \mu \mathrm{g} / \mathrm{ml})$ for half an hour. In order to block the endogenous peroxidase activity, the samples were incubated in the dark for 10 min at room temperature whit $3 \%$ hydrogen peroxide/methanol.

The samples were then washed 3 times each time for 5 min with Tris buffer, then Incubation with the tunnel reaction mixture was performed on the sections for 1 hour at $37^{\circ} \mathrm{C}$.

DAPI solution was then used as counter stain. After that, the sections were washed three times and each time for 5 minutes with Tris buffer and then the number of TUNEL positive neurons in 3 sections of the peri-infarct area of the cortex per animal was carefully counted. The percentage of positive cells against total nuclei was calculated using the Image $\mathrm{J}$ software $\mathrm{v} 1.8$ ( $\mathrm{NIH}$, Wayne Rasband, and USA). 


\section{Super oxide dismutase activity and the Catalase levels}

Using a microplate assay kit (Padtangostar Co, Iran), Super oxide dismutase activity (SOD) and Catalase levels during one week after ischemia was calculated according to the recommended protocol. The hemispheres of the brain with ischemia were homogenized, then poured into a plate and incubated in the assay solution. Optical density was calculated using an ELISA reader (EX800, USA) at $450 \mathrm{~nm}$ (OD 450) for $20 \mathrm{~min}$. Using serial dilutions, the slope of the standard curve was calculated to determine the sample concentration.

\section{Statistical analysis}

The GraphPad Prism version 7.04 was used to analyze the data. To compare the differences between the experimental groups, One-way analysis of variance (ANOVA), was considered followed by Tukey's post hoc test. Data were obtained as mean and standard deviation (mean \pm standard deviation (SD)) and data will be significant when the $p$ value is less than 0.05

\section{Results}

\section{Exosome characterization}

The surface markers on isolated particles was characterised by western blotting to confirm CD9 and CD81 expression. These are conserved biomarkers and widely used for testing exosomes (Fig 1). The result showed that, exosomes were expressed CD9 and CD81 on their surface.

\section{Behavioral test}

\section{Elevated body swing test}

There is no significant difference between EBST test scores in different research groups. In this test, the ratio of rat rotation on the left, which is the healthy part of the brain, to the right, which was the damaged part, which is one in the healthy control group, is examined. The other groups were examined for rat rotation on the left (Figure 2).

\section{Cresyl violet staining}

As shown in Figure 3, Cresyl violet staining was employed to identify the apoptotic cells in brain tissue of MCAO induced rats after 1 week of model induction. The highest quantity of inky cells of neural tissues $(81 \% \pm 3.46)$ were detected in MCAO group by a semi-quantitative method in comparison with the other groups. However, the percentage of the cells died through apoptosis in the MCAO+EXO $(39.33 \pm 0.88)$, $M C A O+R T P A(31.67 \pm 1.33)$ MCAO+RTPA+EXO $(26 \pm 1.52)$ groups were remarkably $(P<0.05)$ lower than the MCAO $(81 \% \pm 3.46)$ group.

\section{Exosomes and rt-PA effects on transcriptional levels of NIrp3 and NIrp1}


The expression of the NIrp3 and NIrp1 genes were quantified to identify the degree of inflammation in the brain tissue of rats before the induction of MCAO (seven days) and also after that, and therapy course in investigational groups. According to figure 5, the levels of NIrp3 and NIrp1 genes expression in the MCAO group were noticeably higher in comparison with the other groups. The monotherapy of either exosome or rt-PA cause to downregulate the expression of the NIrp3 and NIrp1 genes in comparison with the MCAO group $(p<0.05)$. The combined exposure therapy with exosome and rt-PA cause to reduce the levels of NIrp3 and NIrp1 genes expression in MCAO+RTPA+EXO group in comparison with other investigational groups $(p<0.05)$ [Figure 4].

\section{GFAP and IBA1 Expression}

The GFAP expressing cells (Figure 5) were detected by the immunohistochemical analysis following MCAO induction, and the cell counting was done in all investigational groups. The highest percentage $(47.47 \% \pm 1.14)$ of GFAP expressing cells detected in MCAO group (Figure $5 B$ ) in comparison with other investigational groups. The GFAP expressing cell count in the MCAO+EXO $(30.62 \% \pm 0.9)$ and MCAO+RTPA groups $(24 \% \pm 2.08)$ was remarkably decreased in comparison with the MCAO group $(p \leq 0.05)$. The significant difference between the MCAO+EXO and MCAO+ RTPA groups was not observed. In the MCAO+EXO+RTPA group, the degree of GFAP expressing cells was remarkably $(\mathrm{p} \leq 0.05)$ lessen to $21.67 \% \pm 2.02$.

Protein IBA1 expression was show in Figure 6 that measured with IHC methods. Similar to GFAP and histopathological changes of the brain tissue, the highest expression of IBA1 protein belonged to the MCAO group and the therapeutic interventions cause to decrease significantly in IBA1 compared with the MCAO group ( $p \leq 0.05)$. Investigation of the effect of each therapeutic interventions revealed that IBA1 expression in MCAO + RTPA + EXO group decreased significantly in comparison with the MCAO + EXO and control $(p=0.001)$.

\section{Tunel assay}

According to Figure 7 A\&B, MCAO group increased apoptotic cells in brain $(p=0.001$ compared to control group), in consider of therapeutic interventions. It was also found that the greatest decrease in apoptotic cells was in the MCAO + RTPA + EXO group.

\section{Super oxide dismutase activity and the Catalase levels}

Changes in antioxidant enzymes were evaluated by SOD and Catalase measurements (Figure 8, A\&B). The results of this study showed that SOD values in brain tissue of rats with MCAO showed a significant decrease compared to the control group $(p=0.001)$. However, only the MCAO + RTPA + EXO group showed a significant increase compared to the MCAO group $(p=0.001)$. However, changes in other groups were not significant (Figure $8 \mathrm{~A}$ ).

However, all therapeutic interventions were able to increase Catalase activity compared to MCAO group $(p \leq 0.05)$. The largest decrease was also in the MCAO + EXO + rt-PA group (Figure 8 B). 


\section{Discussion}

In spite of various therapies for the protection and recovery of neuronal tissues following the stroke induction, the long-term disabilities would be persistent due to the severe side effects and narrow therapeutic time window (4). Many therapeutic approaches have failed to show a treatment protocol for the complete recovery of neurological functions. Recombinant tissue plasminogen activator (rt-PA) is the only Food and Drug Administration (FDA)-approved drug one for the mitigation of stroke, and it is considered the standard therapeutic regimen for post-stroke patients which it would be effective only if administered at the first hours of stroke onset. The blood-brain barrier can cause limitations for some chemical agents to gain access to the CNS; therefore, many neurological diseases are deprived of effective drugs to be able to penetrate the BBB and enter the target site. Considering this critical issue, nanocarriers are increasingly being designed and developed to be capable of crossing the BBB and serving as a drug delivery system. Nowadays, stem cells have evolved a unique source for the secretion of exosomes, which are considered natural nano-vesicles in biologically active molecules. Exosomes act as paracrine effectors easily interrelate the cells and cross the selective-permeable membranes such as BBB, thus emerging as a multipurpose tool for some therapeutic strategies (20). Therefore, in the present study, as a novel therapeutic vehicle, we investigated the neuroprotective effect of exosomes in combination with rt-PA on rats induced by MCAO. In this research, the bone marrow mesenchymal stem cells derived exosomes applied as a neuroprotective agent alone or in combination with rt-PA. According to our data, the Garcia grading system represented the sensory and movement-related neuronal activity of the brain of rats which showed significant enhancement following the combined exposure therapy with exosome and rt-PA after 1 week of MCAO induction. Although the administration of each compound enhanced Garcia's score, the difference between the treatment groups and the MCAO group was not significant. In line with our study, Xin et al., for the first time, examined the therapeutic efficiency of exosomes derived from MSCs in rats induced by MCAO. They demonstrated that the functional recovery occurred in response to treatment with exosomes (6). Our findings showed that apoptotic cells, which were remarkably increased in the MCAO group, were decreased in rats receiving exosomes alone or in combination with rt-PA, denoting the neuroregenerative and neuroprotective potential of exosomes in the breakdown of clots after the stroke induction.

Exosomes contain miRNA, siRNA, cytosolic, and membrane proteins, including enzymes, growth factors, receptors, and cytokines (21). Accordingly, exosomes derived MSCs have been shown to alter the gene expression and promote brain recovery by changing the miRNA profile expression (22). MSCs and exosomes both have the ability to increase neurite remodeling, neurogenesis, and angiogenesis(7). Moreover, our data demonstrated that GFAP expressing cells, as an astrocyte marker, were lessened within the brain of rats receiving exosome/rt-PA or a combination of both, implying the increased rate of in post-stroke animals. Thus, rt-PA can reanalyze the clogged vessels and enhance neuronal survival through the digestion of fibrin clots, facilitating the performance of exosomes at the site of tissue damage. Several lines of evidence indicated the beneficial effect of MSCs on neuronal functions in patients who are post-stroke $(23,24)$. Wang et al. examined the impact of bone marrow MSCs on rats which underwent spontaneous intracerebral hemorrhage. They showed that intravenously transplanted 
bone marrow MSCs exert beneficial effects on rats which were induced by stroke. Also, Otero-Ortega et al. identified more than 2000 proteins in exosomes, which are derived from MSCs, that many of them were involved in the brain repair process (25). Although exosomes derived from different cells can exert neuroprotection, those derived from MSCs can also reduce inflammation and enhance angiogenesis and neurogenesis after the onest of stroke (24). Likewise, consistent with our study, Zhang et al., for the first time, depicted that MSCs derived exosomes promote the practical recovery after brain lesion via enhancing angiogenesis and neurogenesis and they indicated that exosomes were considered as a competent therapy to reduce inflammation in rats after the onset of infarction (13). In the current study, we presented a novel therapeutic strategy in which MSCs-derived exosomes, in combination with rt-PA, were employed for the enhancement of neurogenesis in rats immediately after MCAO induction. The fidelity of the current approach is due to 1) the breakdown of clogged arteries mediated by rt-PA and 2) the ability of nano-sized exosomes to pass through the BBB, leading to the efficient delivery of miRNA, growth factors, and multiple proteins in the promotion of neurogenesis and angiogenesis in injured neural tissues.

\section{Conclusion}

In conclusion, the usage of exosomes accompany with rt-PA resulted in promotion of functional recovery, neuroprotective activity enhancement, and keeping the cells viable due to neuroinflammatory reduction effect in rats after 7 days of MCAO induction.

\section{Declarations}

\section{Ethical approvaland consent to participate}

All applicable international, national, and/or institutional guidelines for the care and use of animals were followed by the authors.

\section{Consent for publication}

\section{All authors consent for publication.}

\section{Availability of data and material}

Data and material provide a standardised format

\section{Competing interests}

The authors declare that they have no conflicts of interest

\section{Funding}

No funding was received for conducting this study 


\section{Authors' contributions}

Mina ramezani did idea designing, data collection, and data analysis; Mohsen Safakhil performed the experiments and wrote the draft; and Azadeh Mohamadgholi edited the manuscript and did data analysis.

\section{Acknowledgements}

No acknowledgements

\section{Compliance with Ethical Standards}

\section{Disclosure of potential conflicts of interest}

The authors declare that they have no conflict of interest.

\section{Research involving Human Participants and/or Animals}

The welfare of animals used for research was respected. The studies have been approved by a research ethics committee at the institution. (Biology Department, Faculty of Sciences, Central Tehran Branch, Islamic Azad University, Tehran, Iran).

\section{Informed consent}

Not applicable

\section{References}

1. Kim YD, Cha MJ, Kim J, Lee DH, Lee HS, Nam CM et al (2015) Long-term mortality in patients with coexisting potential causes of ischemic stroke. International journal of stroke: official journal of the International Stroke Society 10(4):541-546

2. Allen BS, Buckberg GD (2012) Studies of isolated global brain ischaemia: I. Overview of irreversible brain injury and evolution of a new concept - redefining the time of brain death. European journal of cardio-thoracic surgery: official journal of the European Association for Cardio-thoracic Surgery 41(5):1132-1137

3. Hocum Stone LL, Xiao F, Rotschafer J, Nan Z, Juliano M, Sanberg CD et al (2016) Amelioration of Ischemic Brain Injury in Rats With Human Umbilical Cord Blood Stem Cells: Mechanisms of Action. Cell Transplant 25(8):1473-1488

4. Savitz SI, Fisher M (2007) Future of neuroprotection for acute stroke: in the aftermath of the SAINT trials. Ann Neurol 61(5):396-402 
5. Balami JS, Sutherland BA, Buchan AM (2013) Complications associated with recombinant tissue plasminogen activator therapy for acute ischaemic stroke. CNS Neurol Disord Drug Target 12(2):155-169

6. Xin H, Li Y, Liu Z, Wang X, Shang X, Cui Y et al (2013) MiR-133b promotes neural plasticity and functional recovery after treatment of stroke with multipotent mesenchymal stromal cells in rats via transfer of exosome-enriched extracellular particles. Stem Cells 31(12):2737-2746

7. Xin H, Li Y, Chopp M (2014) Exosomes/miRNAs as mediating cell-based therapy of stroke. Frontiers in cellular neuroscience 8:377

8. Chen J, Li Y, Katakowski M, Chen X, Wang L, Lu D et al (2003) Intravenous bone marrow stromal cell therapy reduces apoptosis and promotes endogenous cell proliferation after stroke in female rat. $J$ Neurosci Res 73(6):778-786

9. Li Y, Chen J, Wang L, Lu M, Chopp M (2001) Treatment of stroke in rat with intracarotid administration of marrow stromal cells. Neurology 56(12):1666-1672

10. Lindvall O, Kokaia Z (2004) Recovery and rehabilitation in stroke: stem cells. Stroke 35(11 Suppl 1):2691-2694

11. Vlassov AV, Magdaleno S, Setterquist R, Conrad R (2012) Exosomes: current knowledge of their composition, biological functions, and diagnostic and therapeutic potentials. Biochim Biophys Acta 1820(7):940-948

12. Barteneva NS, Maltsev N, Vorobjev IA (2013) Microvesicles and intercellular communication in the context of parasitism. Front Cell Infect Microbiol 3:49

13. Zhang Y, Chopp M, Meng Y, Katakowski M, Xin H, Mahmood A et al (2015) Effect of exosomes derived from multipluripotent mesenchymal stromal cells on functional recovery and neurovascular plasticity in rats after traumatic brain injury. Journal of neurosurgery 122(4):856-867

14. Alishahi M, Farzaneh M, Ghaedrahmati F, Nejabatdoust A, Sarkaki A, Khoshnam SE (2019) NLRP3 inflammasome in ischemic stroke: As possible therapeutic target. International journal of stroke: official journal of the International Stroke Society 14(6):574-591

15. Safakheil M, Safakheil H. The Effect of Exosomes Derived from Bone Marrow Stem Cells in Combination with Rosuvastatin on Functional Recovery and Neuroprotection in Rats After Ischemic Stroke. Journal of Molecular Neuroscience. 2020:1-14

16. Wang Y, Ding N, Guan G, Liu G, Huo D, Li Y et al (2018) Rapid Delivery of Hsa-miR-590-3p Using Targeted Exosomes to Treat Acute Myocardial Infarction Through Regulation of the Cell Cycle. J Biomed Nanotechnol 14(5):968-977

17. Maleki SN, Aboutaleb N, Souri F (2018) Berberine confers neuroprotection in coping with focal cerebral ischemia by targeting inflammatory cytokines. J Chem Neuroanat 87:54-59

18. Sicard KM, Fisher M (2009) Animal models of focal brain ischemia. Experimental translational stroke medicine 1:7

19. Mokudai T, Ayoub IA, Sakakibara Y, Lee EJ, Ogilvy CS, Maynard KI (2000) Delayed treatment with nicotinamide (Vitamin B(3)) improves neurological outcome and reduces infarct volume after 
transient focal cerebral ischemia in Wistar rats. Stroke 31(7):1679-1685

20. Zagrean AM, Hermann DM, Opris I, Zagrean L, Popa-Wagner A (2018) Multicellular Crosstalk Between Exosomes and the Neurovascular Unit After Cerebral Ischemia. Therapeutic Implications. Front NeuroSci 12:811

21. Théry $C$, Boussac $M$, Véron P, Ricciardi-Castagnoli P, Raposo G, Garin J et al (2001) Proteomic analysis of dendritic cell-derived exosomes: a secreted subcellular compartment distinct from apoptotic vesicles. J Immunol 166(12):7309-7318

22. Liu FJ, Lim KY, Kaur P, Sepramaniam S, Armugam A, Wong PTH et al (2013) microRNAs involved in regulating spontaneous recovery in embolic stroke model. PloS one 8(6):e66393

23. Knecht T, Borlongan C, Dela Pena I (2018) Combination therapy for ischemic stroke: Novel approaches to lengthen therapeutic window of tissue plasminogen activator. Brain circulation 4(3):99-108

24. Chen J, Chopp M (2018) Exosome Therapy for Stroke. Stroke 49(5):1083-1090

25. Otero-Ortega L, Gomez de Frutos MC, Laso-Garcia F, Rodriguez-Frutos B, Medina-Gutierrez E, Lopez JA et al (2018) Exosomes promote restoration after an experimental animal model of intracerebral hemorrhage. Journal of cerebral blood flow metabolism: official journal of the International Society of Cerebral Blood Flow Metabolism 38(5):767-779

\section{Figures}

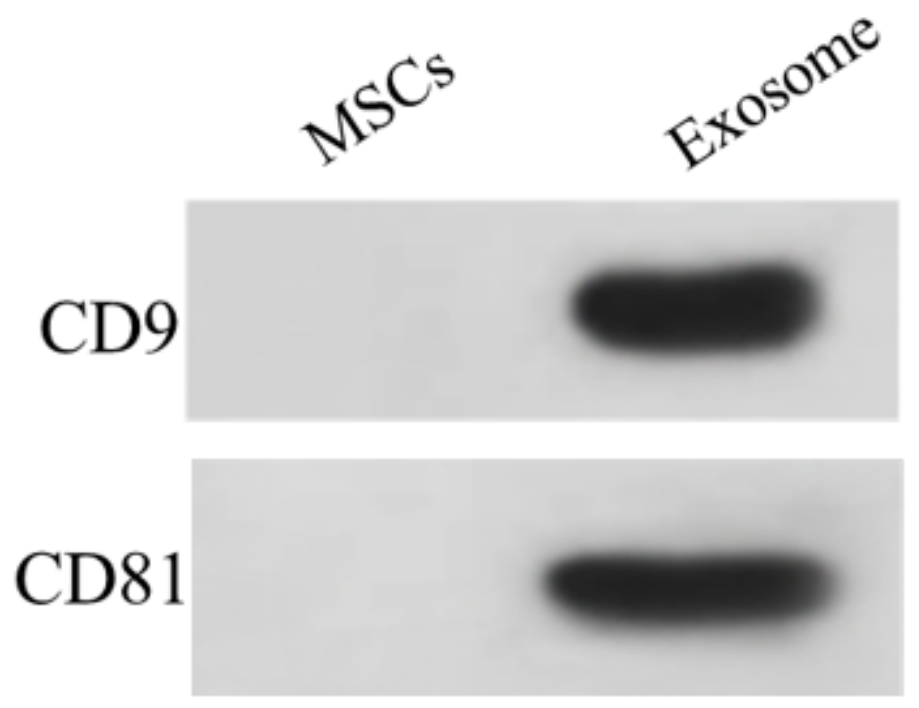

\section{Figure 1}

Characterization of MSC-Exo. Western blot analysis of the exosomal surface markers CD9, CD81. 


\section{DAY7}

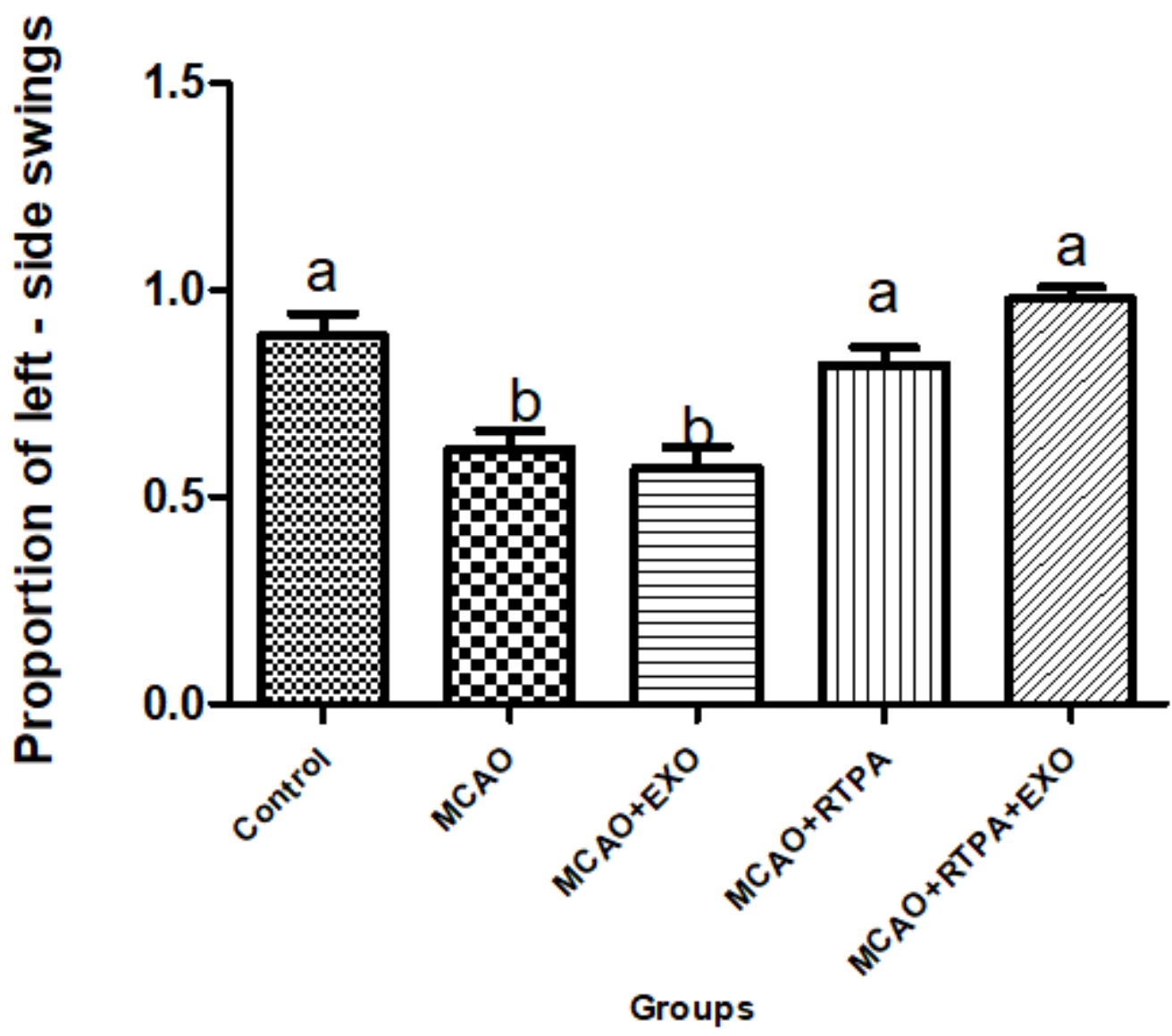

Figure 2

Evaluation of EBST test score in different experimental groups in 7 days. Values are expressed as the means and standard error of the mean (mean \pm SEM). The letters different represent statistically significant differences between the mean values $(P<0.05)$. 

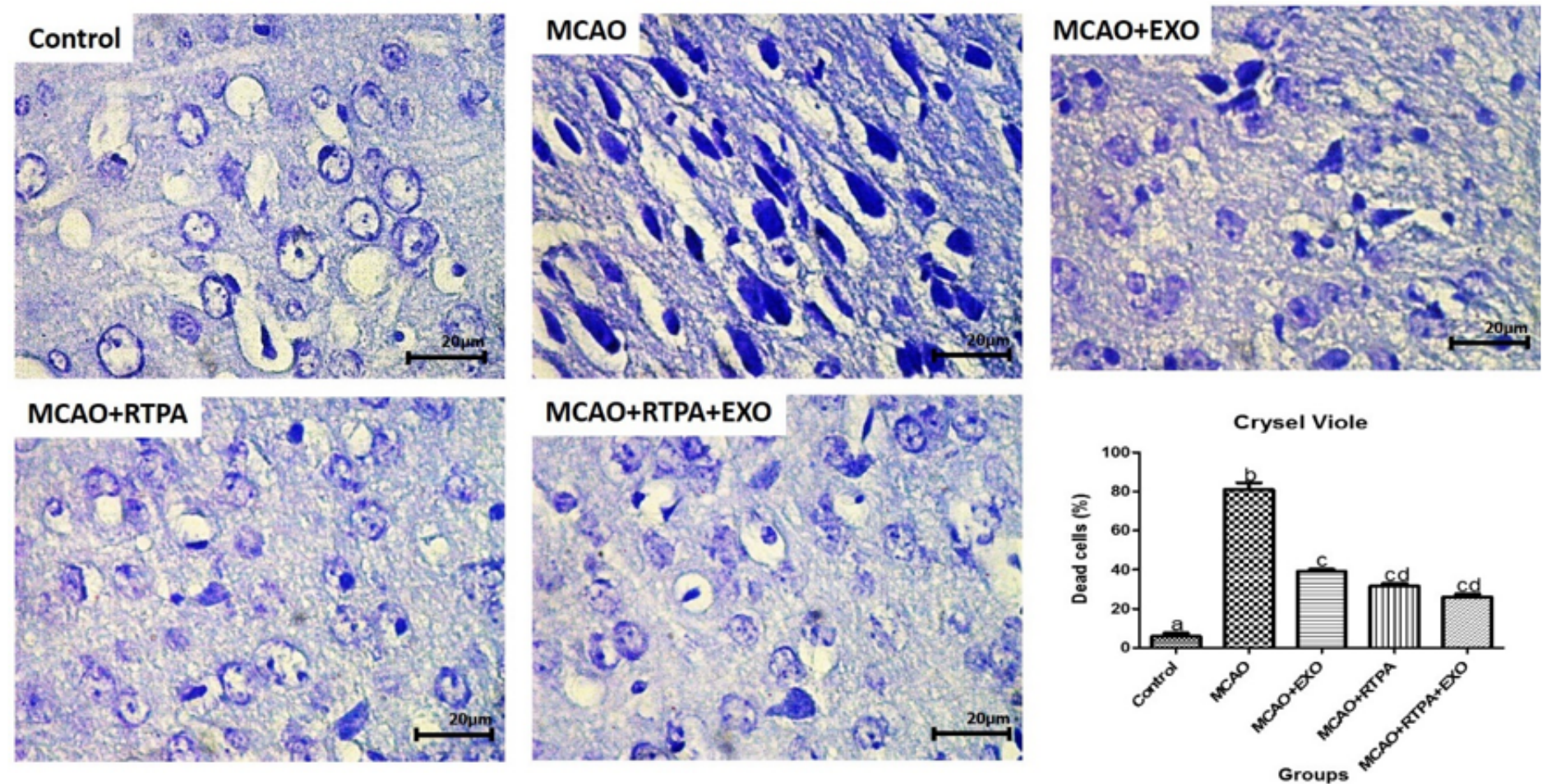

Figure 3

Representative of the penumbral cortex of ischemic hemisphere stained with Cresyl violet stain seven days after the onest of MCAO in all groups. The dead cells are indicated by arrow. The obtained data are represented as the means and standard error of the mean (mean \pm SEM). The different letters represent statistically significant differences between the mean values $(P<0.05)$. -scale bars: $20 \mu \mathrm{m}$.

A)

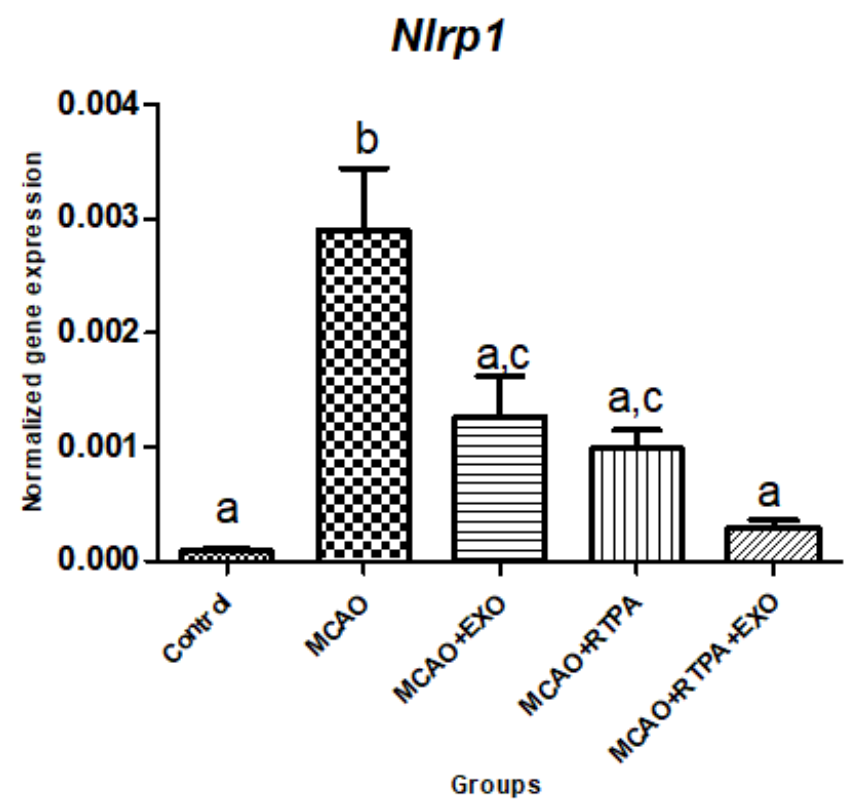

B)

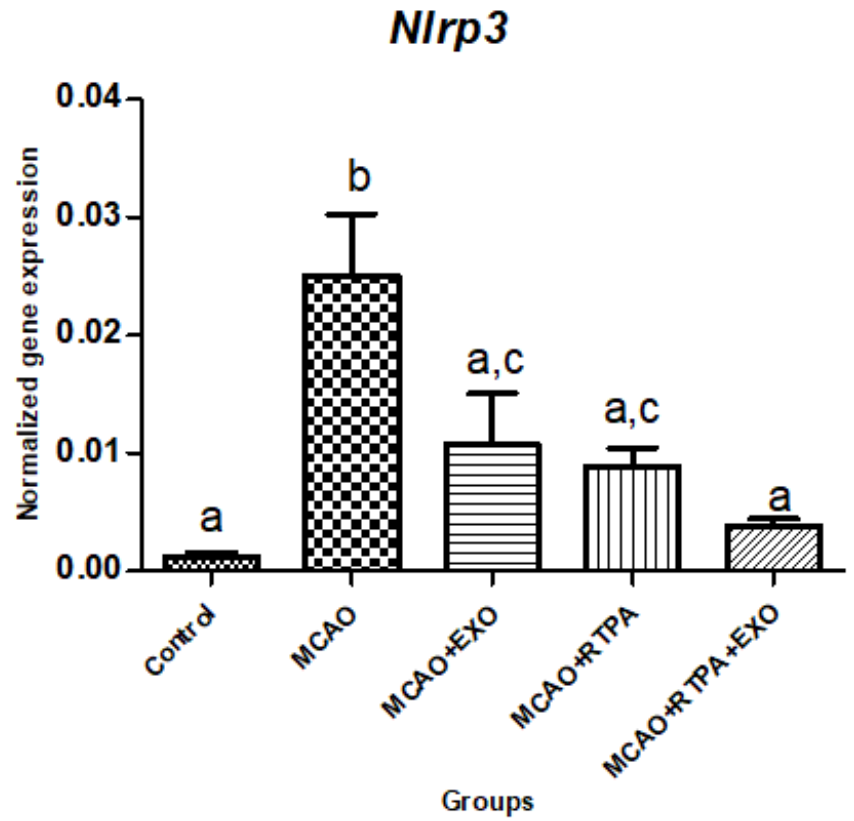




\section{Figure 4}

The impact of rt-PA and exosome on the expression of the (A) Nlrp1 and (B) Nlrp3 genes measured by the real-time PCR analysis in brain tissue of rats after 7 days of MCAO induction. The transcriptional level of each sample was normalized against the expression of Gapdh. The reactions were performed in six separate experiments.
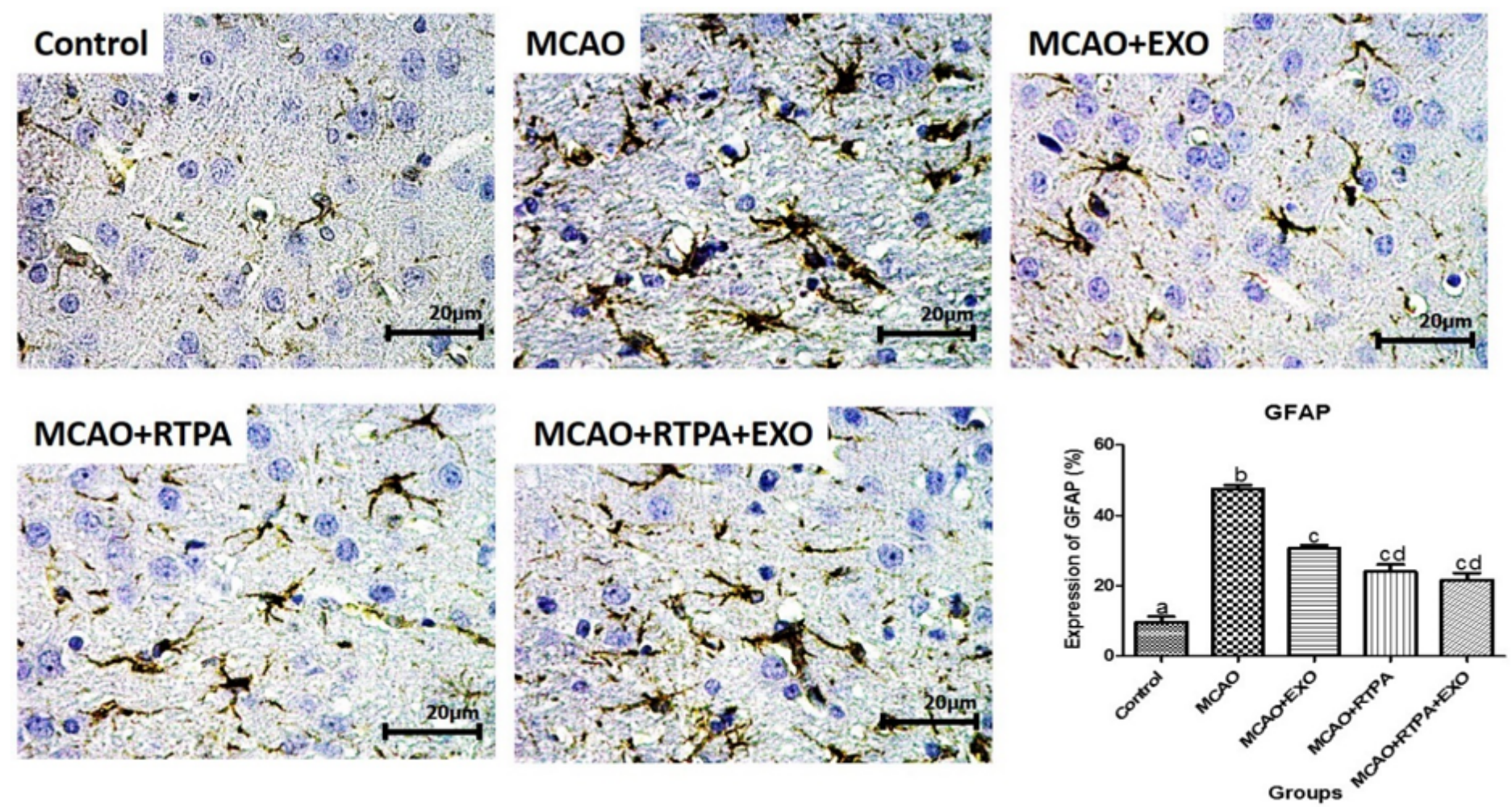

\section{Figure 5}

Immunohistochemical analysis of GFAP-positive cells (astrocytes) in the cortex of rats 7 days after MCAO induction in different experimental groups. The arrow shows GFAP-positive cells. The obtained data are represented as the means and standard error of the mean (mean \pm SEM). The letters represent statistically significant differences between the mean values $(P<0.05)$. -scale bars: $20 \mu \mathrm{m}$. 

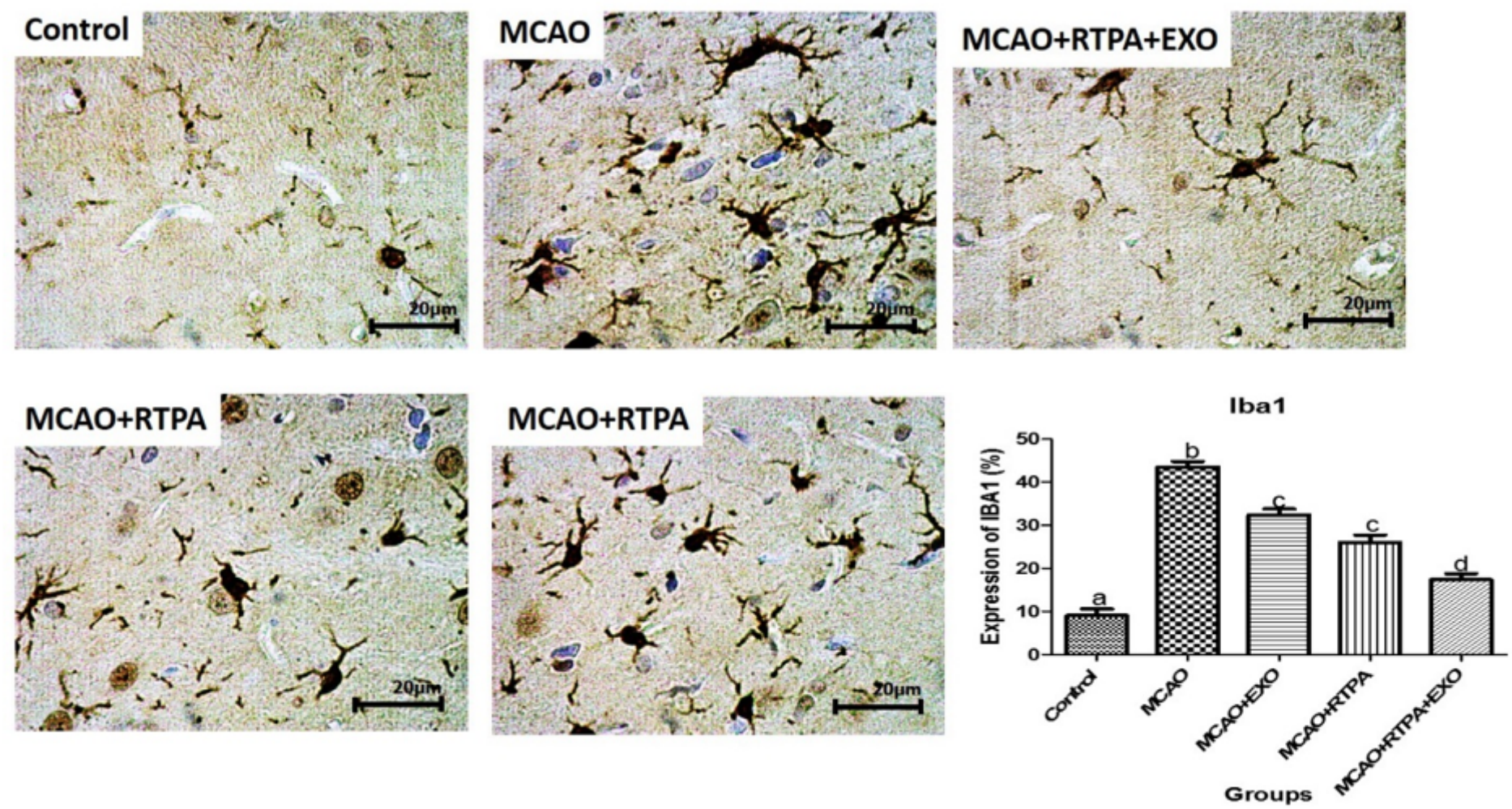

Figure 6

Expression of IBA1 in different groups. The difference signs represent statistically significant differences between the mean values $(P<0.05)$ and the same sign are not significant. Data represent means $\pm S E$ of three experiments. MCAO: middle cerebral artery occlusion, EXO: exosomes, RTPA: recombinant tissue plasminogen activator-scale bars: $20 \mu \mathrm{m}$. 
A)
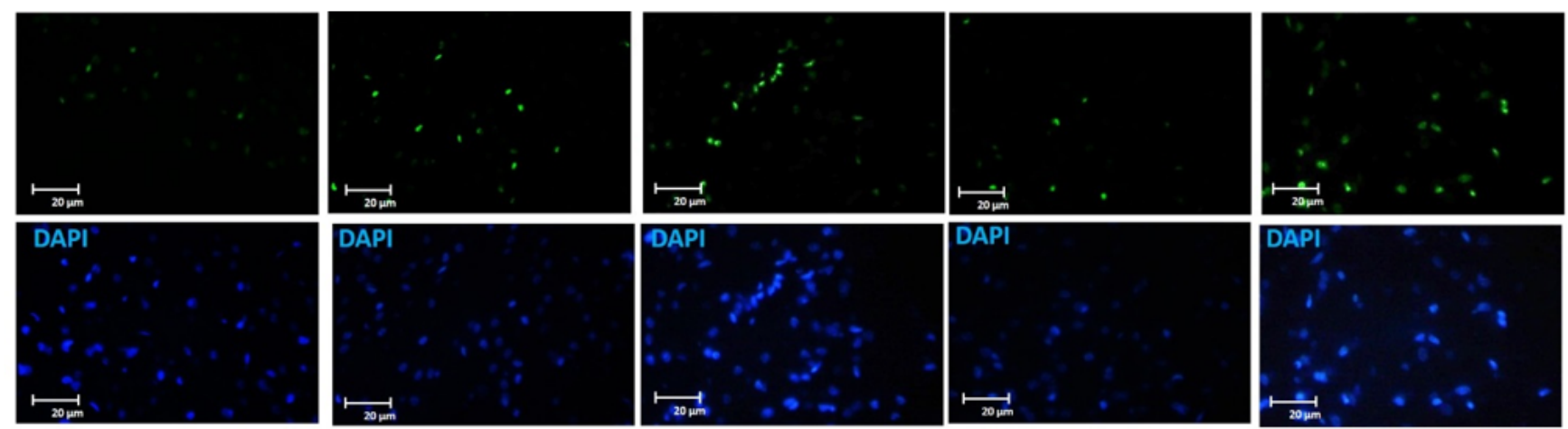

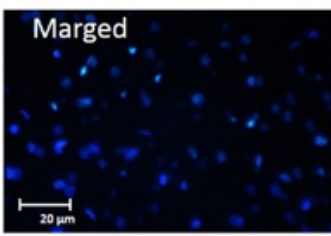

Control

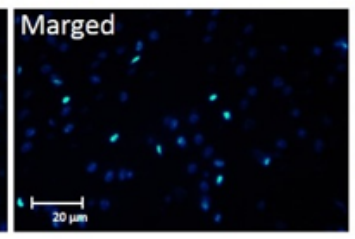

MCAO

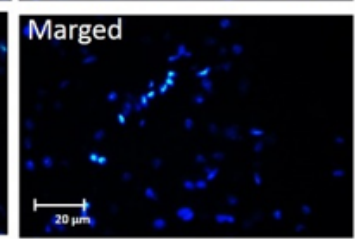

MCAO+EXO

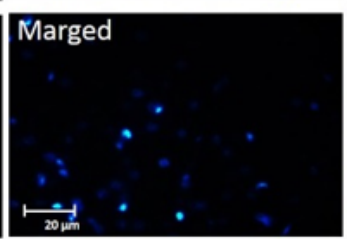

MCAO+RTPA

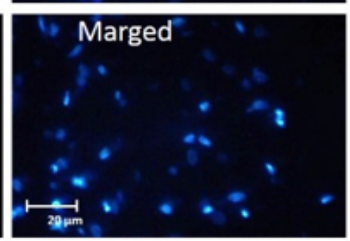

MCAO+RTPA+EXO

B)

\section{Tunel assay}

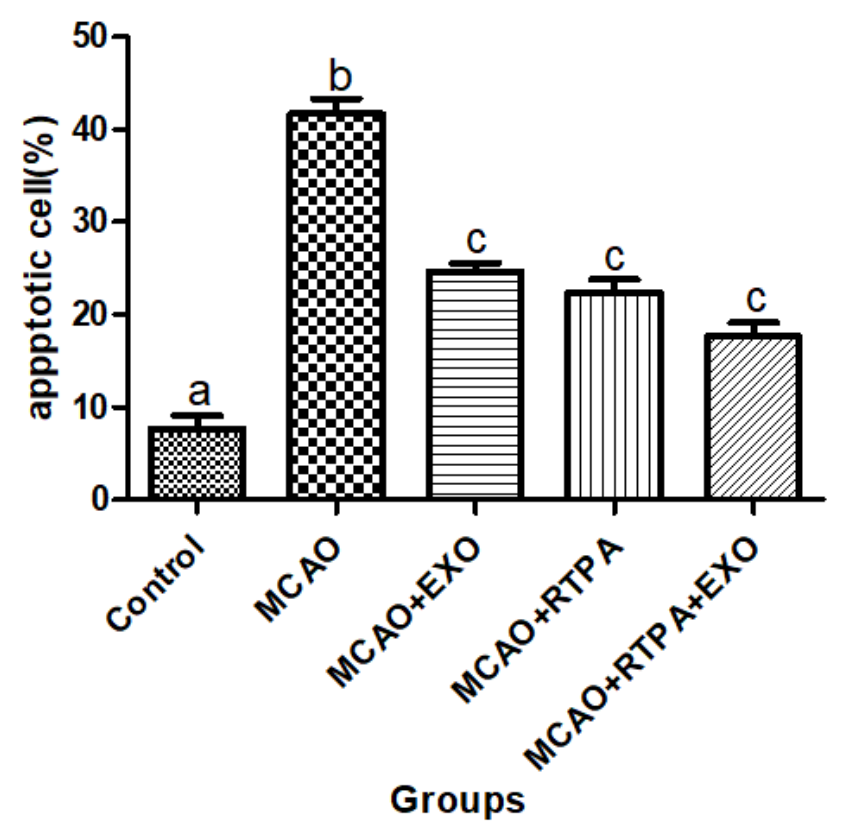

Figure 7

Apoptotic cell in different groups by tunnel assay (A\&B). The difference signs represent statistically significant differences between the mean values $(P<0.05)$ and the same sign are not significant. Data represent means \pm SE of three experiments. MCAO: middle cerebral artery occlusion, EXO: exosomes, RTPA: recombinant tissue plasminogen activator. 


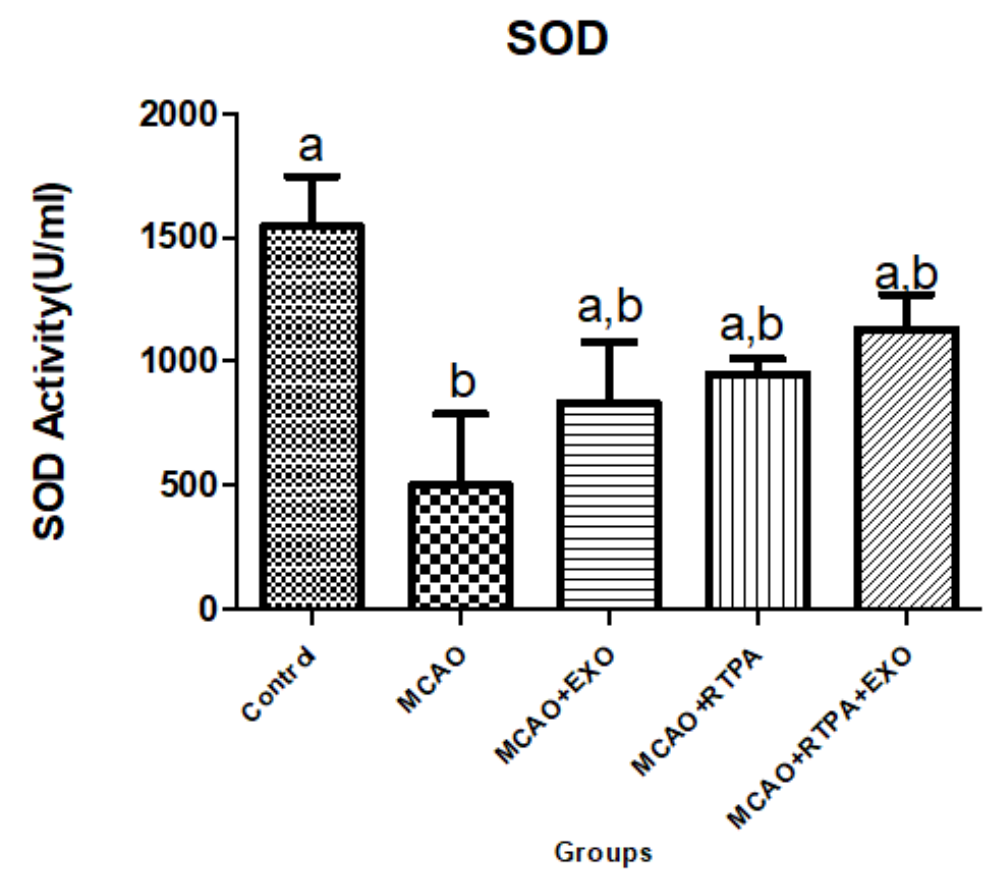

B)

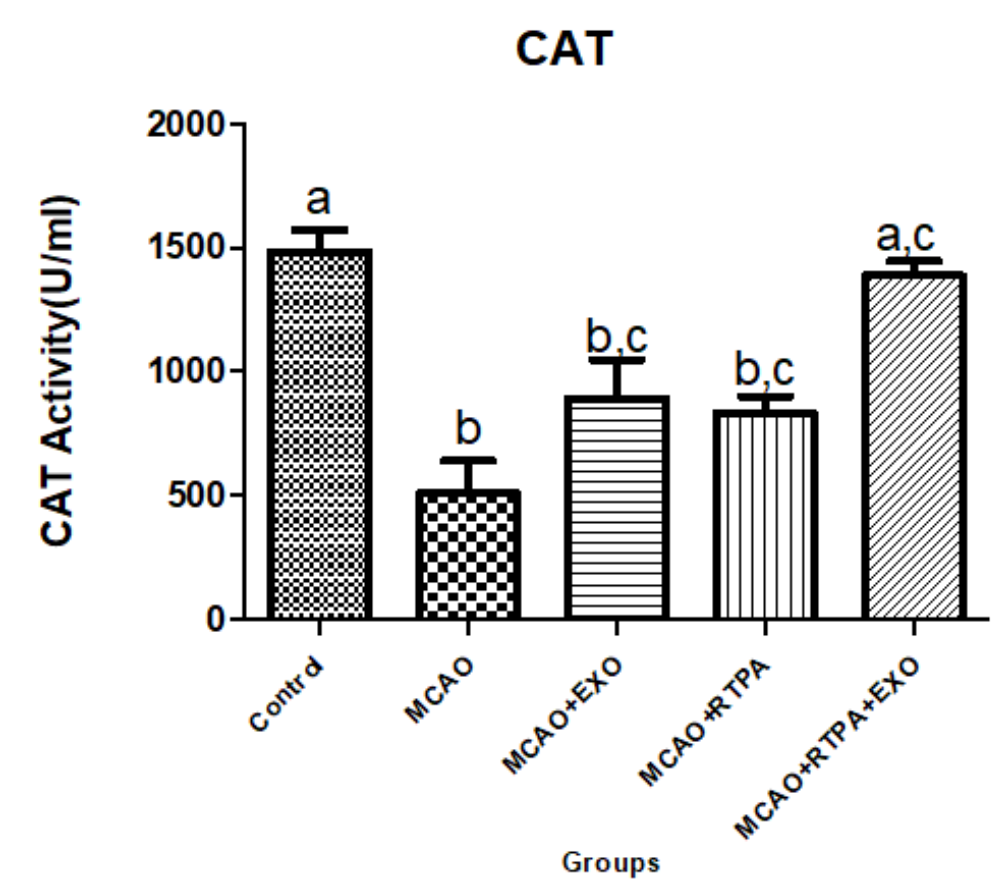

Figure 8

Change in SOD and Catalase in all groups (A\&B). The difference signs represent statistically significant differences between the mean values $(P<0.05)$ and the same sign are not significant. Data represent means \pm SE of three experiments. MCAO: middle cerebral artery occlusion, EXO: exosomes, RTPA: recombinant tissue plasminogen activator. 